\title{
Student Needs: Cognitive as Well as Communicative
}

Marian Tyacke and David Mendelsohn

This paper describes a long-term observational project which focuses on student behaviour in order to examine different learning styles and learning strategies. The implications for syllabus design are then discussed.

\section{BACKGROUND}

ESL practitioners in the seventies and eighties have attempted to take into account students' communicative needs (functional/notional syllabus design, English for Specific Purposes, etc.) as well as their affective needs (humanistic techniques, counselling/learning, suggestopoedia, etc.) with some success. There is increasing concern, however, that students' cognitive needs are not receiving enough attention. In other words, curriculum design rarely takes into account different learning styles and different learning strategies in any systematic way, even though teachers might attempt to deal with individual differences on an ad hoc basis.

Psychologists and linguists have long been fascinated with the learning process, attempting to define and assess language aptitude, or analyzing "good" language learning (Bialystok, 1979; Carroll, 1981; Cummins, 1979; Naiman et al, 1978; Hosenfeld, 1979; and Wesche et al., 1980, among others). As practitioners, we are naturally interested in what successful language learning means; however, our focus has been on individual differences rather than shared characteristics. We contend that language learners (good or bad) develop differently. They move along different paths. They pay attention to different aspects of language. They interpret these aspects differently, and they implement them differently. For a number of years, we have been interested in the implications of this phenomenon, especially in terms of how syllabus design and classroom practices would be affected.

\section{THE GOALS OF THE RESEARCH}

It was decided, therefore, to begin a long-term observational project which would focus on student behaviour in an intensive ESL pro- 
gramme. This programme attracts highly educated students who are either already pursuing a professional career, or hoping to continue academic studies in a North American university. Courses last for six or twelve weeks.

Our investigation was meant to answer the following specific questions:

1. What had others observed/analyzed? What conclusions had been reached? What methods and instruments had they used?

2. What different strategies led to the different patterns we had observed?

3. Even if we could categorize these patterns successfully, what would we do about it? What changes would we implement based on our findings? Would we want to intervene or simply accommodate to the differences? In other words, would we want to explicitly train students to be good language learners, or simply provide them with a richer, more flexible learning environment focussing on teaching strategies?

4. How specifically would we take different strategies into account? For example, would we channel the accurate but inarticulate student into "fluency" classes? Would we give the fluent but inaccurate students grammar rules? Would we force students to pay attention to things they did not naturally or normally pay attention to? In this case, presumably our teaching strategies would conflict with their learning strategies.

5. Depending on how our students are judged by the host culture outside of the classroom, if fluency is prized above accuracy, should we be encouraging one kind of development over another?

6. More immediately, what observation methods and instruments could we use to describe and analyze learning strategies?

\section{PRELIMINARY THEORETICAL CONSIDERATIONS}

Our main goal was to describe and analyze the underlying learning strategies of the students. This required that we clarify some of the key variables discussed in the literature:

\section{Communication Strategies and Learning Strategies}

Corder (1983, p. 16) defines communication strategies as "a systematic technique employed by a speaker to express his meaning when faced with some difficulty." However, he sees a learning strategy as something which makes a positive contribution to the development of the learner's interlanguage system. Candlin observes in Faerch and Kasper (1983, p. xi) that "Learner communication strategies offer, as overt 
behaviour, "windows" on the covert cognitive behaviour of the learner, giving us clues as to how the learner is thinking and coping." However, he cautions us "not to make too facile a link between overt and covert behaviour." And yet it was exactly that link which we felt had to be investigated.

O'Malley et al. (1984, p. 1) differentiate "learning" and "communication" strategies as follows: "the intent of learning strategies is the internalization of certain aspects of the new language, whereas the intent of communication strategies is the immediate negotiation of meaning-usually in a face to face encounter."

Communication strategies are seen, then, as temporary expedients to be retained or rejected depending on their success. Learning strategies, on the other hand, are more likely to effect a permanent change in the learner's repertoire.

\section{Learning Styles/Patterns}

Styles are usually defined as polar opposites: field dependent/independent, tolerant/intolerant of ambiguity, impulsive/reflective etc.; however, what it generally comes down to is the way a given individual prefers to tackle a problem most of the time. Unfortunately, much of the research has been done in a first language setting, but in a second language setting, any categorization may become muddied by other variables. Such characteristics could be exaggerated or distorted by lack of control of the linguistic or sociolinguistic code.

Learning style, for us, is a blanket term which covers a composite of characteristics, a range of behaviours and preferences which are neurologically and/or socially determined. Within this range are the conscious learning strategies which are the focus of our investigation. Presumably, if they are conscious, they are exploitable. In other words, teachers and learners can intervene to change things.

\section{Additional Variables}

Although a review of recent literature suggested that it made sense to investigate what strategies good learners use, and teach poor learners how to do the same, certain studies showed that a whole range of other variables have to be borne in mind.

\section{Cultural background}

Politzer and McGroarty (1985) cite a comparison between Asian and Hispanic groups, and find that Asians are less likely to perform certain traditionally accepted "good learning behaviours" because of cultural constraints. These include asking the teacher questions, volunteering, asking for help, asking others to repeat, and correcting other students. 
This could suggest that what is called "good learning behaviours" in the literature is based on highly ethnocentric assumptions and therefore could be gratuitous advice for certain cultural groups.

Professional specialization and formal education

Adult learners may have very different backgrounds in terms of their professional/occupational training and in terms of how much formal education they have had. Such factors are likely to have significant effects on their language learning behaviours.

\section{Previous English instruction}

Politzer and McGroarty (1985) point out that this, too, is a factor which has to be borne in mind. What the learners are used to is very often assumed to be the best way to learn language, and this colours their future attitudes and selection of strategies.

Strategies that are skill-specific, task-specific or setting-specific

Other variables may also play a part in the effective use of specific conscious strategies. For example, a possible strategy for improving oral/aural skills could be requesting and processing an oral explanation regarding a specific lexical term, whereas this might inhibit good development of contextualization skills when learning to read in another language.

As far as tasks and settings are concerned, Wenden (1983) points out that the generalizations in the literature are based almost exclusively on learning academic tasks in academic settings. She suggests that strategies needed to learn from watching television, or to deal with native speakers outside of the classroom, for example, may be very different.

\section{RESEARCH UNDERTAKEN}

\section{Observational Studies}

Initially, we concentrated on oral performance as a means of building up a profile of communication strategies. A check-list was devised (Mendelsohn et al., 1983) to provide communicative feedback to students in situations when they were interacting spontaneously in classroom activities, building up what Mendelsohn terms "metasociolinguistic awareness."

Further classroom investigation was carried out, notably by Amber, Grandage, McDonough and McNerney (Conference presentation, TESL Canada/TESL Ontario, Nov. 1985). 
Amber carried out an informal investigation in a writing class, noting that students who showed the best improvement were those who actively exploited the resources available to them, including their teachers and classmates. They used clarification, memorization and monitoring strategies effectively, and were good at self-management. (See Chamot (1984), Table 1, for definitions of metacognitive strategies.) Unsuccessful students seemed unable to self-direct, refused to reformulate earlier writing, and seemed to have a lower self-concept than the others.

Grandage explored both the teacher's and learners' perceptions of strategies to improve listening skills. Learners reported their conscious strategies in their own terms, and these included practice, group-work, guessing from context, L1 transfer, note-taking, using key words, visuals, and body language.

McDonough and McNerney compared notes on vocabulary learning strategies in two classes of different proficiency, low-intermediate and advanced, using Rubin's (1981) Observation Schedule of Language Learners. They found that a variety of strategies existed at both levels (for example, memorization, guessing, inferencing, and various kinds of deductive reasoning), but that as students developed in proficiency, they tended to discard less productive strategies, such as memorization. They also consciously used different strategies in different situations (e.g., reading and listening).

\section{The Diary Project}

A more extended project, which began in January, 1985, involves students' keeping records of their own learning development, and focussed interviews with the principal investigators. There are obvious drawbacks in any project which deals with learner introspection and retrospection. Subjectivity, indistinct recall and the desire to please may all cause distortion. Diffuseness may be an added problem, especially when the diary entries are the basis for further discussion.

However, in spite of misgivings, it was decided to carry out a project which would involve ten students, at least one from each proficiency level in an eight level programme. As we were deliberately using the "wide-angled lens" approach, and were simply interested in what patterns emerged, students were not specifically chosen, but were asked to volunteer. Of the original ten volunteers, three soon dropped out, including the one from the lowest class. The seven remaining students who finished the project were, in order of proficiency from low to high:

1) Eiko: Japanese, 51, in the travel industry. 5 years in Canada.

2) Therese: French Canadian, 55, teacher.

3) Yves: French Canadian, 22, an engineering student.

4) Tekke: Indian (L1 Malayalam), 48, a practising minister of his church in Canada. 2.5 years in Canada. 
5) Maria: Chilean, 30, a psychology student. 5 months in Canada.

6) Molly: Chinese from Hong Kong, 36, a T.V. announcer. Less than 1 month in Canada.

7) Jean-Francois: French Canadian, 25, a law student.

All students were asked to keep a diary on a daily basis, noting what they found easy or what they enjoyed, as opposed to what they found difficult or did not enjoy. They could focus on any skill, and on any aspect of that skill. Every second week, they brought the diary to a twenty-minute discussion with one of the investigators. All diaries were collected at the end of the project for further analysis. The appendix contains excerpts from five diaries only, as Maria soon lost interest in keeping her own written record, but was willing to report orally on a regular basis, while Eiko kept hers in Japanese.

It was explained to each student that we were interested in how they developed throughout the course, although any specific discussion on learning strategies was avoided in an attempt not to lead. It was also made clear that they were meant to analyze their own, not the teacher's, performance. In this way, we hoped to find out what they personally found important, and what they chose to pay attention to.

At the end of the project, which was carried out in their free time, they all indicated that they had enjoyed the experience, and felt that their own awareness had increased. Most felt that discussion dealing with their perceived problems was most helpful to them.

Even in such a small group, the overriding pattern that emerged was that learning styles seem to vary significantly. All students indicated conscious learning strategies, although Eiko, with some justification, felt that hers (which depended a great deal on translation) were unsuccessful. Excerpts from the diaries of the lower level students indicate a much greater dependence on the teacher, and on the linguistic code, as we would expect, than those of the more advanced students, except for Molly. She exhibits a high level of discourse competence, both in writing and speaking, but is convinced that accuracy is the most important goal. Her main strategies seem to be frequent practice, memorization and requests for error correction. Tekke is in a transition stage. He knows that vocabulary is not enough, but is not exactly sure what he should be looking for, except that he feels that native models are essential. Maria, although fluent, frequently expresses concern about coherence. Jean-Francois, probably the most sociolinguistically sophisticated, clearly shows a cheerful disregard for linguistic accuracy. He was the only learner who showed a pattern of developing awareness.

\section{Focussed Interviews}

A second project involving a much more homogeneous group (4 
young women, 19-25, whose education was carried out in German) has just been completed. Again, significant differences in learning strategies were apparent even though all four would be considered extremely successful language learners. This will be the subject of a future report.

\section{Current Study}

A project presently underway involves interviews with learners who have been identified by their teachers as successful in different skills. The teachers will also monitor their strategies in the classroom, and a comparison will be made of teacher and student perceptions.

\section{IMPLICATIONS FOR SYLLABUS DESIGN}

Responses in the learning strategy literature divide into what we have termed the cautious "sensitize the teacher" school, versus the "explicitly teach", or "interventionist" school.

\section{The Sensitization Approach}

Naiman et al. (1978, p. 103), in their "good language learner" study argue that with our present knowledge, all we should do is to sensitize teachers and students to different ways different students approach learning: "We do not believe that long lectures on strategies and techniques, or even lengthy discussions on the subject would be particularly profitable." What they advocate at most are "hints" from the teacher and periodic brief exchanges: "We therefore recommend a cautious teaching how-to-learn approach."

A further word of caution is sounded by Naiman et al. for a different reason. They believe (as do we) that learners should be developing their own strategies, and that if the teacher explicitly directs their use of strategies, this will stifle the learner. Finally, Naiman et al. also emphasize the point that strategies and techniques form only a part of language learning, and that many other variables must be taken into account.

\section{The Interventionist/Strategy Development Approach}

On the other hand, O'Malley et al. (March 1985, p. 43) suggest that more research is needed as to which strategies, which tasks, etc. go with which students, but express optimism based on research in reading comprehension, arguing that probably "an extremely powerful learning tool that students currently use inefficiently could be made available with proper direction and support." They argue that teachers should go beyond their "traditional role of providing information" and should 
acquaint students with, and train them to apply, strategies. In O'Malley (September 1985), they make their call for intervention even more explicit. They looked at the effect of training students in different skill areas, and found that it made a significant difference in the case of speaking. Students applied the strategies easily and well. As far as listening was concerned, the success of the strategies training proved to be related to the difficulty of the task and the explicitness of the directions for using the strategies. In effect, if the task was very difficult, students derived little help from learning strategies. They ultimately conclude that classroom instruction in learning strategies can facilitate learning, and call for the identification of good language learner strategies in order to teach them to the poor language learner.

Wenden (1983), in a similar vein, recommends what she calls "curricular strategies"; that is, she addresses the curricular implications of this sort of approach arguing for techniques and materials to expand the learners' repertoires of efficient strategies, and their awareness of various aspects of their language learning. Wenden (October 1985) goes all the way in advocating that we should be actively teaching learning strategies by opening her article with the old proverb: "Give a man a fish and he eats for a day. Teach him how to fish, and he eats for a lifetime." But just as there are many different kinds of rod, different kinds of bait and different fishing locations, all of which offer a variety of choices and experiences, there are different ways of learning language.

\section{CONCLUSIONS}

The central question remains. Should we intervene or not? In other words, should we either have each instructor teach learning strategies appropriate to each skill or introduce a topic into the curriculum which explicitly teaches learning strategies, in a similar way, perhaps, to de Bono's (1978) methods of teaching thinking strategies? Alternatively, should we simply sensitize instructors to the different ways students approach learning, and/or design a syllabus which allows students to choose different paths on the basis of their natural inclinations and preconceived ideas? For example, we could provide highly structured, teacher-centred classes side by side with much looser, more exploratory situations with teacher facilitation. However, we are also mindful of concerns expressed by Widdowson (1984) among others. He asks, "How can we be sure that the routes that learners follow by their own natural inclination will indeed lead them to their objectives more reliably than the directions given explicitly be teachers?"

Unfortunately, apart from the work done by Breen and Candlin 
(1980) on the "negotiated" syllabus, and Tyacke's (1983) "three dimensional" syllabus design, little attention has been paid to the possibility of devising a curriculum in which the syllabus, teaching techniques and materials all offer the learner a number of choices. In Tyacke (1983), it was suggested that syllabus design take into account different learning patterns. Students are roughly divided into three categories: those who are concerned with being accurate, (probably the largest group), those who are concerned with being appropriate, and those who are concerned with being articulate. In Canale and Swain's (1980) terms, the first group seem to be developing grammatical competence and attempting to master the linguistic code; the second group seem to be developing sociolinguistic competence and are more sensitive to topic, participants and context; the third group seem to be developing discourse competence and are able to combine and connect utterances so that they are perceived as being fluent, but not necessarily accurate. Clearly, students develop to some extent in all three areas, but they follow preferred paths which are not always successful but obviously important to them. These paths, however, are extremely difficult to discern and describe, especially as our assessment procedures do not adequately chart or measure different stages in that development.

In summary, much of what we and our students report will of necessity be subjective; and, as Allwright (1983, p. 201) points out, such language learning observation may be open to criticism: "Perhaps the basic question is, can we test hypotheses in some way that meets any generally accepted criteria for any serious research enterprise, or can we only illuminate issues?" However, with him, we agree that observation is "the best we can do."

We may not make a decision on the interventionist/non-interventionist issue for a long while, certainly not until we are sure that our future design will help and not harm our students. Whether it be a multi-dimensional syllabus, or a complex match of teaching/learning styles, a specific class in learning strategies or a gentle sensitization process remains to be seen. Certain very important questions still have to be answered before such a decision can be made, and more teacher and student input will be considered in the process.

\section{REFERENCES}

Allwright, Dick (1983). Classroom-centred research on language teaching and learning: A brief historical overview. TESOL Quarterly, 17(2), June, 191204.

Bialystok, E. (1979). The role of conscious strategies in second language proficiency. Canadian Modern Language Review, 35, 372-394.

Breen, M.P. \& Candlin, C.N. (1980). The essentials of a communicative cur- 
riculum in language teaching. Applied Linguistics, 1(2), Oxford University Press.

Canale, M. \& Swain, M. (1980). Theoretical bases of communicative approaches to second language teaching and testing. Applied Linguistics, 1(1), Oxford University Press.

Carroll, J.B. (1981). Twenty-five years of research on foreign language aptitude. In K.C. Diller (Ed.), Individual differences and universals in language learning aptitude, 83-118. Rowley, Mass.: Newbury House.

Chamot, A. Uhl \& O'Malley, J.M. (1984). Using learning strategies to develop skills in english as a second language. Focus 16, September.

Corder, S. Pit (1983). Strategies of communication. In Faerch, C. \& Kasper, G. (Eds.) Strategies in interlanguage communication, 16-17. London: Longman.

Cummins, J. Cognitive/academic language proficiency, linguistic interdependence, the optimum age question and some other matters. Working Papers on Bilingualism, No. 19, 121-129.

DeBono, E. (1976). Teaching thinking. London: Temple Smith.

Faerch, C. \& Kasper, G. (Eds.) (1983). Strategies in interlanguage communication. London: Longman.

Hosenfeld, C. (1976). Learning about learning: discovering our students' strategies. Foreign Language Annals 9 (2), 117-129.

Naiman, N., Frohlich, M., Stern, H.H. \& Todesco, A. (1978). The good language learner. Research in Education Series/7, Ontario Institute for Studies in Education.

O'Malley, J.M., Chamot, A. Uhl, Stewner-Manzanares, G., Kupper, L. \& Russo, R.P. (1985). Learning strategies used by beginning and intermediate ESL students. Language Learning, 35(1), March, 21-46.

O'Malley, J.M., Chamot, A. Uhl, Stewner-Manzanares, G., Russo, R.P. \& Kupper, L. (1985). Learning strategy applications with students of English as a second language. TESOL Quarterly, 19(3), September, 557-584.

Politzer, R.L. \& McGroaty, M. (1985). An exploratory study of learning behaviors and their relationship to gains in linguistic and communicative competence. TESOL Quarterly, 19(1), March, 103-124.

Rubin, J. (1981). Study of cognitive processes in second language learning. Applied Linguistics, II(2), 118-131.

Tyacke, M. (Nov. 1983). Levelling the multi-dimensional syllabus. Paper presented at Symposium on Curriculum Design at the Ontario TESL Conference, Toronto, Ontario.

Wenden, A. (1983). Literature review: The process of intervention. Language Learning, 33(l), 103-121.

Wenden, A. (1985). Learner strategies. TESOL Newsletter, xix(5), 1.

Wesche, M., Wells, W., \& Edwards, H.P. (1980). Foreign language aptitude and intelligence. In K.C. Diller (Ed.) Individual differences and universals in language learning aptitude, 119-154. Rowley, Mass.: Newbury House.

Widdowson, H.G. (1984). The implications of a communicative approach to language teaching. Unpublished MS. 


\section{THE AUTHORS}

Marian Tyacke is Coordinator of ESL Programs in the School of Continuing Studies at the University of Toronto. She is also involved in teacher training.

David Mendelsohn is a lecturer in ESL at the School of Continuing Studies at the University of Toronto. In addition, he is Academic Coordinator of the TESL Certificate program at the university.

\section{APPENDIX}

\section{THERESE}

\section{Interviewer Comments}

- prefers interaction with teacher to interaction with other students (she is a language teacher)

- writing proficiency way ahead of talking: talking hesitant, many errors

- listens to radio, T.V. news

- consciously "practices".

1) One student is interfering with the teacher and explaining what the teacher is trying to make clear. It is difficult for me to concentrate and I miss the explanation.

2) As I played an active part in the dialogue, I became more interested and I participated more in the discussion that followed. I regretted that each pupil did not have a copy of the dialogue and that we did not have time to read the text beforehand. For me, the first reading was for pronunciation and I could not understand all the sense of the sentences.

3) When I was engaged in informal conversation with another student, the teacher overheard some mistakes in our grammar and he corrected it immediately. I found this type of correction very helpful.

\section{YVES}

\section{Interviewer Comments}

- enjoys linguistic analysis

- underlines new vocabulary items-checks dictionary

- doesn't like long discussions

- doesn't like to work without explanations.

1) We were supposed to practise the asking forms, but I have been disappointed, because most of the time the participants didn't try very carefully to ask the questions in a correct form.

2) I think we should take the time to analyze what we read and how the text is built.

3) We received a list of some words, and we tried to figure out the meaning of those words. As a homework, we have had to build a sentence with each of these words. It's a good exercise, and it helps us to remembering the words and their signification.

4) At home, sometime I read the newspaper and when there's something strange for me in the way the writer used to say something, I ask some explication to the teacher. 


\section{TEKKE}

\section{Interviewer Comments}

- wants to speak "better English"

- wants to use English "effectively"

- sets high standard for himself

- not a risk-taker.

1) I need lot of improvement in well pronounced and properly stressed reading.

2) I seen many people (E.S.L.) who know less vocabulary than I do speak better than me. Why? With a smaller vocabulary and comperatively less experience some people (E.S.L.) are able to communicate effectively in their day to day life. I can imagine two possible reasons. First, I speak or more correctly, my social environment forces me to speak more than two languages apart from English. Secondly, I am a bit shy.

3) One other problem is lack of use of gimmick (gambits) or techniques to avoid suspension during conversation.

4) I think the best way to learn a language is to listen from the mouth of its native speakers.

\section{MOLLY}

\section{Interviewer Comments}

- writes simpler forms to avoid mistakes

- admits she sacrifices style for accuracy

- focusses constantly on linguistic rules

- language learning is "effort," "memorizing," "preparation."

1) I need a teacher to point out my mistakes.

2) I know this kind of idioms involves the accurate usage of prepositions. That is rather difficult. One good way of learning them is by memorizing them, which I have always been doing.

3) My weakness is in listening, more drilling would be given to me on this particular field.

4) This kind of presentation (ORAL) surely is useful and constructive. Although one has to spend a lot of effort in the preparation, not only on research, but also on rehearsalts, yet one finds it rewarding in a way that one has to do the talk in a very formal way so that special attention has to be paid to grammar, especially tense, to volcabruary and to the contents.

\section{JEAN-FRANCOIS}

\section{Interviewer Comments}

- although much less "accurate" than Therese, perceived by most to be much more advanced student

- very articulate/fluent when making points in interview

- good at emphasis

- risk-taker 
1) I think we don't review enough the rules of grammar. However, I must point out that this situation is getting better. Effectively, contrary to the first, we have initiate in the second week a little revision of some rules of grammar. Consequently, before to adopt a definitive position on this question, I prefer to let passed one or two weeks.

\section{1/02/85}

2) The teacher asked us to determine the conditions of a good conversation ... the evaluation will be made on the following points:

- keeping the conversation smoothly flowing

- bringing in all participants

- show capability to follow directions of conversation and follow up on points made.

I am not sure of the pertinence of this kind of exercise in a talking class. When I decided to come to $U$. of $T$. for the English program, I wanted to correct my deficient pronunciation. In other words, I wished that the teacher will give me exercises to improve my pronunciation.

If we analyse the work proposed by our teacher, we can see that the evaluation is not based on our pronunciation but rather on our manner to manage a conversation. I think that this kind of exercise is not an exercise of language; it is an exercise of public relations.

\section{$28 / 02 / 85$}

3) In the second part of the course, we learned how to emit an opinion without insulting the person who speak with you. Good exercise of talking.

\section{$04 / 03 / 85$}

4) We have seen our performance on T.V.... it is very amazing and interesting to see ourself on T.V. We can remark our defaults and correct it. For myself, it is necessary that I try to avoid the hesitations like euh, ah, etc. Equally, I make a bad use of my tenses of verb. Finally, my pronunciation is completely FRENCH.

\section{2-04-85}

5) If I have some reserves on certain aspects of the course, I must say that I am globally satisfied.

On the one hand, I have written in my journal that I don't agree with the public relations aspect of the course. Now, I must mitigate this affirmation.

Before to come here, I assimilated Talking and pronunciation. Consequently, I was very surprised to see how this course put the emphasis on conversation rather than on pronunciation.

Now, I realize that conversation is a step before pronunciation. In other words, pronunciation is a specialized area in a more general field called Talking. So, before to concentrate on pronunciation, you have to pass by the stage of talking. 